\title{
Backward association in serial learning as a function of prior paired-associate training
}

RICHARD DOLIMSKY AND JOSEPH J. JUSKA

THE UNIVERSITY OF TOLEDO

Young, Milauckas, $\mathcal{E}$ Bryan (1963) found mean trials to criterion in serial learning to be faster if a prior pairedassociate list was compatible with later serial order than if it was incompatible. The present experiment added a pairedassociate list constructed by reversing the members of each pair in the "compatible" group. This "backward" group differed significantly from the "incompatible group," but was similar to both a "compatible" and an unrelated control group.

In a recent study, Young, Milauckas, \& Bryan (1963) investigated serial learning as a function of prior paired-associate (PA) learning. They found that when the ordering of items in one group (Group P) led to the development of $S-R$ units in the PA list that were identical to those in the serial list, fewer mean trials on the serial list were necessary to reach criterion than if the ordering of the prior PA list developed S-R units that were incompatible with later serial learning (Group N). For example, if the serial task involved learning of items in an $A-B-C-D-E$ etc. order, superior serial performance occurred in Group P, where the prior PA pairs were A-B, C-D, B-C, $D-E$, etc., than in Group $N$, where the pairs might be C-E, A-C, B-D, E-B, etc. A neutral group (Group $O)$, in which the PA items were completely different from the serial items, was significantly better than Group N. Although the point needs clarification, it would appear, but for one comparison, that there was no difference between Groups $P$ and $O$.

The "double-function" nature of the PA lists in Groups $P$ and $N$ allows each item (except one) to serve as a stimulus and also (with one exception) as a response. In accord with the Asch \& Ebenholtz (1962) "availability" principle of backward association as interpreted by Horowitz, Norman, \& Day (1966), every item (discounting the two excepted ones) on the PA list should develop equal availabllity for recall. While it is true that an item does not serve as both stimulus and response in the same pair, it appears as Horowitz et al (1966) note: "According to the (availability) principle, however, the latent backward association could be made overt by any operation that increased the stimulus availability"' (p. 5). That is, backward association could be increased in a pair, if the stimulus in that pair was a response in another pair equally often. The results of Horowitz et al (1966) support this view. In the Young et al (1963) study both forward and backward associations would be Incompatible with serial learning in Group $N$. However, in Group $P$, the forward associations would be compatible and the backward associations would be incompatible in later serial learning. Consequently, the backward associations developed in PA learning of Group $P$ would, in fact, interfere with subsequent serial learning since they would counter the positive transfer expected in this group. For example, in learning item $C$ as a response to $B$ in the serial list, performance in Group $P$ would be facilitated by the prior B-C PA learning, but there would be backward interference of $A$ from the prior learning of the $A-B$ pair (cf., Umemoto \& Hilgard, 1961). The result of this interaction could be zero transfer and this might explain the general lack of difference between Group $P$ and Group $O$, the group in which neither facilitation nor interference is presumed to occur.

Proceeding further, suppose, prior to learning a serial list, A-B-C-D etc., a backward PA list was learned, e.g., B-A, C-B, D-C, etc. In this case, call it Group B, the forward associations acquired in PA learning would now be incompatible with subsequent serial learning, but the backward associations should be facilitative. If forward and backward associations were equal in strength, as the availability principle suggests they would be after PA learning of this type, serial performance in Group B should be similar to Group $P$, but better than Group $\mathrm{N}$, where only incompatible associations are developed. Although the notion of backward association presented above leads clearly to this prediction for Group B, it is also clear that the nature of the facilitation-interference interaction is subjected here to only an indirect evaluation. The experiment also should clarify the relation between Groups $P$ and $O$ regarding PA to serial list transfer.

\section{Mefhod}

The Ss were 72 undergraduate students randomly assigned to four groups of $18 \mathrm{Ss}$ each.

The method, although similar to that used by Young et al (1963), included several major changes. Three PA lists of nine adjective pairs were constructed from a serial list of nine items. The PA lists were all of the "complete" double-function type in that each item (without exception) served as both a stimulus in one pair and a response in another. Aside from this difference, Groups $\mathrm{P}, \mathrm{O}$, and $\mathrm{N}$ were constructed consistently with those of Young et al (1962): Group P developed S-R units in the PA task that were identical to those in the serial list; Group $N$ learned PA units incompatible with later serial learning, and Group O learned a PA list composed of different 
Table 1

Mean Trials to Criterion and Standard Deviations for Four Groups in Serial Leaming

\begin{tabular}{ccc} 
Group & Mean Trials to Criterion & SD \\
\hline P & 9.22 & 4.98 \\
O & 11.44 & 5.95 \\
B & 12.50 & 7.41 \\
N & 16.67 & 7.65 \\
\hline
\end{tabular}

words than those used in the serial list. In addition, Group B learned a PA list in which the stimulus and response members of the Group $P$ pairs were reversed. All adjectives were of low similarity and were chosen from either the Young et al (1963) experiment or from Melton (Hilgard, 1951). Each S learned the appropriate PA list for 20 trials using five different orders of presentation. A 2:2 sec rate was used with a 4 sec intertrial interval.

Following PA learning the serial items were presented in a "closed cycle" list in which Ss learned an unbroken series with no gap introduced (Glanzer \& Dolinsky, 1965). The same items, in the same order, were learned in all four groups. Learning proceeded at a $2 \mathrm{sec}$ rate to a criterion of two successive errorless trials.

\section{Results and Discussion}

There was no difference in total items correct between the four groups on the last 19 PA trials $(F=1.985$, $\mathrm{df}=3 / 68)$; the first trial was used only for study. Mean trials to criterion and standard deviations for the serial list are presented in Table 1. Overall mean differences were significant ( $F=3.812$, $\mathrm{df}=3 / 68, \mathrm{p}<.025$ ). Individual comparisons using a Newman-Keuls procedure indicated Groups $B$ and $O$ to be significantly superior to Group $N$ at the .05 level; Group $\mathrm{N}$ and Group $\mathrm{P}$ differed significantly at the .01 level. Groups $B, O$, and $P$ did not differ significantly.

The results of this experiment basically replicate those of Young et al (1963) in regard to the trials to criterion performance of Groups $P, O$, and N. Of course, any comparison between the two experiments should take into account the present use of a "complete" double function PA list, a "closed cycle" serial list, and a different level of PA training. The similarity between Groups $P$ and $B$ is consistent with the interpretation and results offered by Horowitz et al (1966) with free association. With each item appearing equally often in the stimulus and response positions during PA learning, substantial backward strength apparently was developed among the pairs in Group B to equal the forward strength developed in Group P. Further, the incompatible bonds, backward in Group $\mathbf{P}$ and forward in Group B, presumably could have maintained the equalization introduced by these facilitative effects. The result, compared with Group $O$, would be no net transfer to the serial task. Consequently these three groups did not differ, although their performance was superior to that of Group $\mathrm{N}$ where both forward and backward associations were incompatible. It should be noted that while the means of Groups $P$ and $B$ do not differ significantly at the end of PA learning (4.50 and 4.89, respectively), the level of learning is only moderate. Young \& Jennings (1964) have noted that, in backward learning following double function PA learning, negative transfer increases. Consequently, it is possible that at the moderate level obtained in the present experiment, the bi-directional strength was nearly equal.

Nevertheless, the present results suggest that the role of backward associations might be considerable in transfer from PA to serial learning.

\section{References}

Asch, S. E., \& Ebenholtz, S. M. The principle of associative symmetry. Proc. Amer. Phil. Soc., 1962, 106, 135-163.

Glanzer, M., \& Dolinsky, R. The anchor for the serial position curve. J. verbal Learn. verbal Behav., 1965, 4, 267-273.

Hilgard, E. R. Methods and procedures in the study of learning. In S. S. Stevens (Ed.), Handbook of experimental psychology. New York: Wiley, 1951. Pp. 517-567.

Horowitz, L. M., Noman, S. A., \& Day, R. S. Availability and associative symmetry. Psychol. Rev., 1966, 73, 1-15.

Umemoto, T., \& Hilgard, E. R. Paired-associate learning as a function of similarity: Common stimulus and response items within the list. J. exp. Psychol., 1961, 62, 97-104.

Young, R. K., \& Jennings, P. C. Backward learning when the same items serve as stimuli and responses. J. cxp. Psychol., 1964, $66,64-70$.

Young, R. K., Milauckas, E. W., \& Bryan, J. D. Serial learning as a function of prior paired-associate training. Amer. J. Psychol., $1963,76,82-88$. 